\title{
ANALISIS KEUNTUNGAN USAHA KEDAI KOPI "BABA BUDAN" JALAN RODA DI KOTA MANADO
}

\author{
William Marcel Tanwijaya \\ Ribka Magdalena Kumaat \\ Caroline B. D. Pakasi
}

\begin{abstract}
This study aims to analyze the profitability of the coffee shop business "Baba Budan" so that it can be known in detail the amount of profit each month earned business coffee shop "Baba Budan" in the culinary area on the wheel road in Manado City. Data used in this study primary data obtained by conducting direct interviews with business owners using questionnaires, and secondary data obtained from literature studies in the form of literature, written sources or documents that have relevance to this research. Data analysis method used is descriptive analysis, using business profit analysis, then continued with analysis of Return of Cost Ratio, then presented in table form. The results of this study indicate that the business coffee shop "Baba Budan" gives monthly profit of $R p$. 4.208.028,2, with $R / C$ ratio of 1,45. So it can be concluded that the culinary business is a profit to run because the value of $R$ / $C$ more than 1 . This shows that every Rp. 1 production costs incurred by coffee shop owners are able to provide cash in the form of revenue of Rp. 1,45. Where the total revenue is still greater than the total cost of production and this business for each month.
\end{abstract}

Keywords: profit analysis, coffee shop business "Baba Budan", Manado City

\begin{abstract}
ABSTRAK
Penelitian ini bertujuan untuk menganalisis keuntungan usaha kedai kopi "Baba Budan" sehingga dapat secara rinci diketahui besaran keuntungan setiap bulanyang diperoleh usaha kedai kopi "Baba Budan" dikawasan kuliner di jalan roda di Kota Manado. Data yang digunakan dalam penelitian ini data primer yang diperoleh dengan melakukan wawancara langsung dengan pemilik usaha dengan menggunakan daftar pertanyaan, dan data sekunder diperoleh dari studi kepustakaan berupa literatur, sumber tertulis atau dokumen yang memiliki relevansi dengan penelitian ini. Metode analisis data yang digunakan yaitu analisis deskriptif, dengan menggunakan analisis keuntungan usaha, kemudian dilanjutkan dengan analisis Return of Cost Ratio, lalu disajikan dalam bentuk tabel. Hasil penelitian ini menunjukan bahwa usaha kedai kopi "Baba Budan" memberikan keuntungan setiap bulannya sebesar Rp. 4.208.028,2, dengan rasio R/C sebesar 1,45. Hal ini menunjukan bahwa setiap Rp. 1 biaya produksi yang dikeluarkan oleh pemilik usaha kedai kopi mampu memberikann pengembalian berupa penerimaan sebesar Rp. 1,45. Dimana total penerimaan masih lebih besar dari total biaya produksi dan usaha ini mengalami keuntungan setiap bulannya.
\end{abstract}

Kata kunci: analisis keuntungan, usaha kedai kopi "Baba Budan”, Kota Manado 


\section{PENDAHULUAN}

\section{Latar Belakang}

Kopi merupakan salah satu minuman yang mendunia. Sejalan dengan perkembangan zaman atau gaya hidup maka kebiasaan mengkonsumsi kopi setiap harinya berubah. Pada zaman dulu masyarakat biasanya mengonsumsi kopi hanya pada pagi dan malam hari, tetapi sekarang masyarakat dapat minum kopi kapan saja sehingga terjadi peningkatan konsumsi kopi. Minuman ini sangat banyak digemari baik dari kalangan remaja hingga dewasa.

Masyarakat di Kota Manado gemar bertemu dengan rekan-rekannya sambil minum kopi dan atau mencicipi berbagai makanan lokal. Inilah salah satu alasan di bukanya kawasan wisata kuliner di Jalan Roda di Kota Manad. Kawasan ini sudah berdiri sejak tahun 1960 dan berhasil mendorong anggota masyarakat untuk membuka usaha di bidang usaha ini. maka untunk melihat keuntungan kedai kopi "Baba Budan" adalah dengan cara menganalasis keuntungan usaha dan analisis Return of Cost Ratio.

\section{Pengertian Industri}

Industri adalah suatu usaha atau kegiatan pengolahan bahan mentah atau barang setengah jadi menjadi barang jadi barang jadi yang memiliki nilai tambah untuk mendapatkan keuntungan. Usaha perakitan atau assembling dan juga reparasi adalah bagian dari industri. Hasil industri tidak hanya berupa barang, tetapi juga dalam bentuk jasa.

\section{Faktor-faktor Keberhasilan Dalam Usaha}

Usaha adalah semua aktifitas, yang mencari keuntungan dengan mengusahakan kebutuhan barang dan jasa kepada orang lain(Wewengkang dan Rotinsulu 2017).

$$
\text { Menurut Hendry Faizal (2007) }
$$

keberhasilan usaha pada hakikatnya adalah keberhasilan dari bisnis mencapai tujuanya. Keberhasilan usaha merupakan utama dari sebuah perusahaan dimana segala aktivitas yang ada didalamnya ditujukan untuk mencapai suatu keberhasilan.

\section{Modal Usaha}

Modal sangat diperlukan agar usaha yang dilaksanakan dapat berjalan dengan lancar. Modal tersebut dari modal materil dan modal non materil, besarnya modal tersebut tergantung pada bentuk usaha tataboga yang dikelola. Jumlah modal yang disediakan akan mempengaruhi besar kecilnya usaha tersebut.

\section{Indikator Keberhasilan Usaha}

Keberhasilan usaha akan sangat tergantung pada suatu bagian usaha biasa berkembang. Salah satu indikator untuk menggukur keberhasilan suatu usaha yang paling mudah untuk diamati adalah laba yang diperoleh perusahaan (Suryana, 2003).

\section{Fungsi Biaya}

Biaya merupakan kas atau nilai setara kas yang dikorbankan untuk barang atau jasa yang diharapkan memberi manfaat pada saat ini atau di masa mendatang bagi organisasi (Simamora, 2002).

\section{Konsep Penerimaan}

Total peneriman adalah jumlah produksi dikalikan dengan harga jual yang berlaku (Wilson, 2007). Menurut Kotler (2006), total penerimaan merupakan jumlah uang yang diterima pengusaha rumah makan sebelum dipotong total biaya atau biasa disebut pendapatan kotor setiap bulan dan dinyatakan dalam rupiah ( $\mathrm{Rp})$.

\section{Rumusan Masalah}

Berdasarkan latar belakang maka yang menjadi perumusan masalah dalam penelitian ini adalah berapa keuntungan yang di dapat dalam 1 bulan dalam usaha Kedai Kopi Baba Budan di Jalan Roda di Kota Manado.

\section{Tujuan Penelitian}

Tujuan dari penelitian ini adalah untuk menganalisis keuntungan usaha Kedai Kopi Baba Budan.

\section{Manfaat Penelitian}

Maanfat dari penelitian ini di harapkan dapat memberikan informasi mengenai gambaran potensi usaha di Jalan Roda di Kota Manado, melalui contoh yang diperoleh dari kelayakan usaha kedai kopi Baba Budan, serta menjadi bahan masukan dan informasi mengenai potensi usaha kedai kopi di kawasan wisata kuliner di jalan roda bagi Pemerintah Kelurahan Wenang Utara di Kota Manado. 


\section{METODOLOGI PENELITIAN}

\section{Waktu dan Tempat Penelitian}

Penelitian ini dilaksanakan di Kedai Kopi "Baba Budan" di Kota Manado. Penelitian ini dilakukan mulai dari bulan Oktober sampai bulan Desember 2017 mulai dari tahap persiapan proposal sampai penyusunan laporan penelitian.

\section{Metode Penelitian}

Metode yang di gunakan dalam penelitian ini adalah metode studi kasus, data yang dibutuhkan dalam penelitian ini adalah data primer dan data sekunder. Data primer menggunakan teknik wawancara langsung dengan pemilik kedai kopi "Baba Budan" dengan menggunakan daftar pertanyaan yang telah di persiapkan terlebih dahulu, Sedangkan data sekunder diperoleh dari studi kepustakaan berupa literatur, sumber tertulis atau dokumen yang memiliki relevansi dengan penelitian ini.

\section{Konsep Pengukuran Variabel}

Adapun variabel-variabel yang di amati dan di ukur dalam penelitian ini :

1. Harga jual menu minuman kopi yang di sediakan pada setiap hari kemudian di jumlahkan dalam satu bulan. (Rp/bulan)

2. Biaya Produksi Pembuatan Minuman Kopi (Rp/bulan)

3. Jumlah biaya dalam penelitian ini yaitu jumlah Biaya yang di keluarkan pengusaha dalam 1 bulan untuk menyediakan menu minuman kopi yang di tawarkan, meliputi:

a) Biaya tetap ( $\mathrm{Rp} / \mathrm{bulan}$ ) yang terdiri dari:

- Pajak usaha , yaitu retribusi pengusaha kedai kopi bagi penerimaan Negara yang di bayarkan kepada pemerintah per bulan.

- Biaya penyusutan, yaitu komponen biaya yang secara tidak langsung di keluarkan pengusaha untuk setiap bulan produksi dalam hal ini.

b) Biaya variabel (Rp/bulan), meliputi :

- Bahan baku pembuatan minuman kopi, terdiri dari biji kopi kotamobagu, biji kopi Modayag, biji kopi Bali Kintamani, kopi Aceh, kopi Toraja, Gayo, kopi susu/kopi hitam, gula,susu.
- Biaya pengadaan Peralatan Pelengkap Lainnya

- Upah tenaga kerja setiap bulan.

- Biaya iuaran tagihan listrik dan air

- Biaya transportasi, yaitu biaya distribusi bahan baku dari pasar ke lokasi usaha.

4. Penerimaan, yaitu jumlah uang yang diterima pengusaha kedai kopi sebelum dipotong total biaya atau biasa disebut pendapatan kotor setiap hari dan dinyatakan dalam rupiah $(\mathrm{Rp})$.

\section{Analisis Data}

Untuk mendeskripsikan profil usaha kedai kopi "Baba Buban" di Kota Manado, maka analisis data dilakukan dengan menggunakan metode analisis deskriptif dan disajikan dalam bentuk tabel. Sedangkan untuk mengetahui tingkat keuntungan usaha kedai kopi akan menggunakan analisis keuntungan usaha dengan formulasi :

$$
\mathrm{I}=\mathrm{TR}-\mathrm{TC}
$$

$\mathrm{I}=$ Income/Keuntungan Usaha $(\mathrm{Rp})$

$\mathrm{TR}=$ Total Revenue $/$ Total Penerimaan $(\mathrm{Rp})$

$\mathrm{TC}=$ Total Cost/Total Biaya Produksi (Rp)

Untuk mengetahui usaha kedai kopi layak dilanjutkan atau tidak, digunakan analisis Return of Cost Ratio yang merupakan perbandingan penerimaan dengan total biaya produksi untuk menganalisis kelayakan usaha (Wilson, 2007).

Analisis ini menggunakan model persamaan sebagai berikut :

$$
\mathrm{R} / \mathrm{C}=\mathrm{TR} / \mathrm{TC}
$$

Dimana $: \mathrm{R} / \mathrm{C}=$ Indeks Kelayakan Usaha

TR $=$ Total Penerimaan

$\mathrm{TC}=$ Total Biaya Produksi

\section{HASIL DAN PEMBAHASAN}

\section{Deskripsi Lokasi Penelitian}

\section{Profil Usaha Kedai Kopi "Baba Budan"}

Usaha kedai kopi Baba Budan berdiri sejak tahun 2015 atau sudah berdiri selama 3 tahun dengan pemilik bernama bapak Azhary Awal. kedai kopi ini terletak di kawasan kuliner di jalan roda di Kota Manado, usaha kedai kopi ini menyediakan minuman kopi sebagai hidangan utamanya, kedai kopi ini juga menyajikan 
beberapa minuman lainnya juga seperti teh dan bebarapa snack-snack dan rokok sebagai menu tambahan, yang memberikan kontribusi bagi penghasilan usaha Kedai Kopi "Baba Budan". Operasional usaha ini berjalan selama 7 hari dengan jam operasional selama 13 jam per hari. Sejak jam 10.00 sampai 23.00 kecuali hari jumat dan minggu jam operasionalnya dari jam 14.00 sampai 23.00,usaha ini dijalankan oleh 2 orang tenaga kerja (barista) dengan upah 1.800 .000 perbulan. Dalam menjalankan usaha ini, jumlah cangkir yang terjual tiap harinya kurang lebih 60 cangkir Sehingga total omzet (penerimaan kotor) untuk penjualan minuman kopi di kedai baba budan adalah sebesar Rp. 13.505.000 untuk bulan desember.

\section{Menu Minuman}

Usaha kedai kopi baba budan menyediakan berbagai macam variasi minuman kopi. Jenis minuman kopi yang di tawarkan cenderung biasa ditemui di kedai kopi lainnya yang membedakan kedai kopi baba budan dengan kedai lainya yaitu kualitas kopi tersebut. Harga yang ditawarkan untuk menu kopi bervariasi mulai Rp. 7.000 sampai Rp. 15.000 per cangkir. Produk minuman kopi paling mahal dengan harga Rp.15.000/cangkir, sedangkan produk minuman dengan harga paling murah $\mathrm{Rp}$. 7.000/cangkir.

Tabel 1. Daftar Nama Menu Minuman Kopi di Kedai Kopi

\begin{tabular}{|c|c|c|c|c|}
\hline No & $\begin{array}{c}\text { Nama Menu } \\
\text { Produk }\end{array}$ & $\begin{array}{c}\text { Jumlah } \\
\text { Terjual } \\
\text { (Cangkir) } \\
\end{array}$ & $\begin{array}{c}\text { Harga Produk } \\
\text { Per Cangkir } \\
(\mathrm{Rp})\end{array}$ & $\begin{array}{c}\text { Total } \\
\text { Penerimaan } \\
(\mathbf{R p})\end{array}$ \\
\hline & Kopi & & & \\
\hline 1 & Kotamobagu & 485 & 7.000 & 3.395 .000 \\
\hline 2 & Kopi Modayag & 201 & 15.000 & 3.015 .000 \\
\hline 3 & $\begin{array}{l}\text { Kopi Aceh } \\
\text { Gayo }\end{array}$ & 164 & 15.000 & 2.460 .000 \\
\hline 4 & Kopi Bali & 156 & 15000 & 2340000 \\
\hline 5 & Kopi Toraja & $\begin{array}{l}150 \\
153\end{array}$ & $\begin{array}{l}15.000 \\
15.000\end{array}$ & $\begin{array}{l}2.240 .000 \\
2.295 .000\end{array}$ \\
\hline Total & & 1.159 & & 13.505 .000 \\
\hline
\end{tabular}

Hasil penelitian ini menunjukan bahwa total penerimaan kedai kopi "Baba Budan" dari penjualan menu minuman kopi pada bulan desember 2017 paling banyak bersumber dari penjualan kopi kotamobagu, yaitu tingkat dengan tingkat penerimaan sebesar Rp. 3.395.000. Total penerimaan kedai kopi "Baba Budan" pada bulan Desember menunjukan angka sebesar Rp.13.505.000.

\section{Biaya Produksi}

Biaya merupakan pengeluaran dalam produksi yang tidak dapat dihindarkan. Biaya mempunyai peran yang sangat penting dalam pengambilan keputusan setiap usaha. Besarnya biaya yang dikeluarkan untuk memproduksi akan sangat berpengaruh keuntungan yang akan diperoleh dalam suatu bisnis.

Biaya produksi adalah semua biaya yang dikeluarkan dalam pembuatan minuman kopi. Komponen biaya dibagi atas biaya tetap dan biaya variabel. Biaya tetap yang difokuskan dalam penelitian ini adalah biaya penyusutan peralatan yang digunakan dan besaran pajak usaha yang harus di tiap tahunnya.

\section{Biaya Tetap}

Biaya tetap adalah biaya yang tidak tergantung dari besar kecilnya volume produksi. Dalam artian, Biaya tetap menjadi jenis biaya yang bersifat statis (tidak berubah) dalam ukuran tertentu.

\section{Biaya Penyusutan Alat}

Biaya penyusutan alat adalah biaya yang secara tidak langsung dikeluarkan oleh pemilik usaha untuk setiap tahun produksi.

\section{Rekapitulasi Biaya Tetap}

Komponen biaya tetap yang dihitung pada usaha kedai kopi "Baba Budan" adalah biaya penyusutan alat sebesar Rp.31.805,2/ bulan dan biaya pajak usaha sebesar Rp.1.000.000/bulan. Sehingga hasil penelitian ini menunjukan bahwa total biaya tetap yang dikeluarkan pemilik kedai kopi "Baba Budan" setiap bulannya adalah sebesar Rp.1.031.805,2 .

Tabel 2. Rata-rata Biaya Penyusutan Alat Produksi Pembuatan

\begin{tabular}{ccccc}
\multicolumn{2}{c}{ Mama Alat yang } \\
$\begin{array}{c}\text { Digunakan Dalam } \\
\text { Produksi }\end{array}$ & $\begin{array}{c}\text { Harga } \\
\text { Awal (Rp) }\end{array}$ & $\begin{array}{c}\text { Harga } \\
\text { akhir } \\
\text { (Rp) }\end{array}$ & $\begin{array}{c}\text { Umur } \\
\text { Ekonomis } \\
\text { (bulan) }\end{array}$ & $\begin{array}{c}\text { Biaya } \\
\text { Penyusutan } \\
\text { (Rp) }\end{array}$ \\
\hline Grinder & 100.000 & 0 & 24 & $4.166,6$ \\
Scale & 150.000 & 0 & 24 & 6,250 \\
Thermo & 125.000 & 0 & 36 & $3.472,2$ \\
Aeropress & 100.000 & 0 & 36 & $2.777,7$ \\
Vietnam Drip & 70.000 & 0 & 24 & $2.916,6$ \\
Syphon Drip & 200.000 & 0 & 36 & $5.555,5$ \\
Kompor & 500.000 & 0 & 120 & $4.166,6$ \\
V60 & 60.000 & 0 & 24 & 2.500 \\
Aqua Galon & 100.000 & 0 & 60 & $1.666,6$ \\
\hline Total & & & & $\mathbf{3 3 . 4 7 1 , 8}$ \\
\hline
\end{tabular}


Berdasarkan pada Tabel 2, menunjukan bahwa alat penyusutan yang digunakan untuk memproduksi minuman kopi dalam 1 bulan sebesar Rp.31.805,2. Jenis alat penyusutan tertinggi adalah scale dengan biaya sebesar $6.250 /$ bulan, sedangkan jenis alat penyusutan terendah adalah aqua galon dengan biaya sebesar Rp.1.666,6/bulan.

\section{Biaya Variabel}

\section{Biaya Bahan Baku}

Biaya bahan baku dalam proses pembuatan pembuatan minuman kopi meliputi bahan dasar pembuatan kopi. Tabel 3 menunjukan bahwa komponen biaya bahan baku pembuatan minuman kopi berupa bahan biji kopi arabika, robusta dan bahan pelengkap susu, gula.

Tabel 3. Rata-rata Bahan Baku Pembuatan Minuman Kopi pada Bulan Desember 2017

\begin{tabular}{|c|c|c|c|c|}
\hline No & Bahan Baku & $\begin{array}{c}\text { Pemakain } \\
\text { Bahan } \\
\text { (Kg/karton) }\end{array}$ & $\begin{array}{c}\text { Harga } \\
\text { Beli } \\
\text { (Rp/kg) }\end{array}$ & $\begin{array}{c}\text { Total } \\
\text { Biaya } \\
\text { (Rp/bulan) }\end{array}$ \\
\hline 1 & $\begin{array}{l}\text { Kopi } \\
\text { Kotamobagu }\end{array}$ & $20 \mathrm{~kg}$ & 90.000 & 1.800 .000 \\
\hline 2 & $\begin{array}{l}\text { Kopi } \\
\text { Modayag }\end{array}$ & $5 \mathrm{~kg}$ & 150.000 & 750,000 \\
\hline 3 & $\begin{array}{l}\text { Kopi Aceh } \\
\text { Gayo }\end{array}$ & $3 \mathrm{~kg}$ & 200.000 & 600,000 \\
\hline 4 & $\begin{array}{l}\text { Kopi Bali } \\
\text { Kintamani }\end{array}$ & $3 \mathrm{~kg}$ & 200.000 & 600,000 \\
\hline 5 & Kopi Toraja & $3 \mathrm{~kg}$ & 200.000 & 600,000 \\
\hline 6 & Susu & 2 karton & 585.000 & 1.170 .000 \\
\hline 7 & Gula & $55 \mathrm{~kg}$ & 13.000 & 715,000 \\
\hline 8 & Kertas Filter & 2 dos (200pcs) & 85.000 & 170,000 \\
\hline & Total & & & 6.405 .000 \\
\hline
\end{tabular}

Berdasarkan Tabel 3, dapat dilihat bahwa jumlah bahan baku Kopi Kotamobagu dengan total harga tertinggi adalahRp. $1.800 .000 /$ bulan, sedangkan untuk bahan baku terendah kertas filter sebesar Rp. 170.000/bulan. Sehingga hasil bahan baku pembuatan minuman kopi yang dikeluarkan pemilik kedai kopi "Baba Budan" setiap bulannya adalah sebesar Rp. 6.405.000.

\section{Biaya Pengadaan Peralatan Pelengkap}

Dalam pengadaan peralatan pelengkap, seperti wifi, lampu, dan sebagainya. harus sesuai dengan kebutuhan kedai kopi, dimana dengan adanya fasilitas seperti wifi bisa meningkatkan jumlah pengujung.
Tabel 4. Rincian Biaya Pengadaan Peralatan Pelengkap Lainnya pada Bulan Desember 2017

\begin{tabular}{llcrr}
\hline No & Nama Barang & Jumlah & $\begin{array}{c}\text { Harga } \\
(\mathbf{R p})\end{array}$ & $\begin{array}{c}\text { Total Biaya } \\
(\text { Rp/bulan) }\end{array}$ \\
\hline 1 & Bahan Bakar & 2 & 20.000 & 40.000 \\
& (LPG) & & & \\
2 & Wifi & 1 & 250.00 & 250.000 \\
3 & Lampu & 2 & 20.000 & 40.000 \\
4 & Buku Nota & 1 & 7.500 & 7.500 \\
& Sabun Cuci & 2 & 13.000 & 26.000 \\
5 & Tangan & & & \\
\hline & Total & & & $\mathbf{3 6 3 . 5 0 0}$ \\
\hline
\end{tabular}

Hasil penelitian ini menunjukan bahwa bahan pelengkap tertinggi yaitu wifi yang digunakan dalam sebulan dengan biaya pengadaan sebesar Rp.250.000/bulan, sedangkan biaya pengadaan terendah buku nota Rp. 7.500/bulan. Total biaya pengadaan peralatan pelengkap di kedai kopi Baba Budan sebesar Rp. 363.500/bulan.

\section{Biaya Tenaga Kerja}

Penyediaan tenaga kerja Penyediaan tenaga kerja merupakan cerminan dari kualitas sumber daya manusia yang ada, pemilik kedai kopi dibantu oleh 2 orang karyawan tetap. perlu adanya pembagian jam kerja di kedai ini, karena jam operasional kedai kopi berlangsung selama 13 jam setiap hari sehingga perlu di lakukan pembagian shift jam kerja. Tugas utama 2 orang karyawan (barista) ini membuat minuman kopi,pemilik bertugas di bagian kasir. Gaji karyawan diberikan setiap bulan dengan upah Rp. 3.600.000/bulan.

\section{Biaya Transportasi}

Transportasi digunakan untuk memudahkan pemilik berbelanja, sehingga biaya transportasi yang diperhitungkan dalam penelitian ini adalah biaya yang dikeluarkan oleh pemilik kedai kopi untuk berbelanja bahan baku minuman. Kegiatan berbelanja dilakukan setiap bulan untuk memunuhi stock persediaan bahan baku perbulan seperti gula, dan susu. Dimana transportasi yang digunakan motor pribadi dengan biaya sebesar Rp. 50.000/bulan. 


\section{Rekapitulasi Biaya Variabel}

Komponen yang tergolong biaya variabel adalah biaya pembelian bahan baku minuman sebesar Rp.4.400.000, biaya pengadaan peralatan sebesar $\mathrm{Rp} 363.500$, biaya tenaga kerja sebesar Rp.3.600.000, biaya iuran tagihan listrik dan air Rp. 250.000 dan biaya transportasi sebesar Rp.50.000. Total biaya variabel yang dikeluarkan untuk menjalankan usaha kedai kopi "Baba Budan" sebesar Rp. 8.413.500.

\begin{tabular}{lr} 
Tabel 5. & $\begin{array}{r}\text { Rekapitulasi } \\
\text { Pembuatan Minuman Kopi }\end{array}$ \\
\hline Jenis Biaya & \multicolumn{1}{c}{ Jumlah (Rp) } \\
\hline Biaya Penyusutan Alat & $33.471,8$ \\
Pajak Usaha & 600.000 \\
Biaya Bahan Baku & 4.400 .000 \\
Biaya Pengadaan & 363.500 \\
Biaya Tenaga Kerja & 3.600 .000 \\
Biaya Tagihan Listrik dan & 250.000 \\
Air & 50.0000 \\
Biaya Transportasi & $\mathbf{9 . 2 9 6 . 9 7 1 , 8}$ \\
\hline Total Biaya Produksi
\end{tabular}

Hasil penelitian ini menunjukan bahwa terdapat 6 faktor biaya yang diperhitungkan dalam pelaksanaan usaha kedai kopi ini, yaitu biaya penyusutan Rp. 33.471,8/bulan, biaya pajak usaha Rp. 600.000/bulan, biaya pengadaan bahan baku Rp. 4.400.000/bulan, biaya pengadaan pelengkap $\mathrm{Rp}$. 363.500/bulan, biaya tenaga kerja Rp. 3.600.000/bulan, Biaya Tagihan listrik dan air Rp. 250.000 dan biaya untuk transportasi sebesar Rp. 50.000 maka total biaya produksi usaha kedai kopi "Baba Budan" pada bulan desember mencapai Rp. 9.296.971,8/bulan.

\begin{tabular}{lr} 
Tabel 6. & \multicolumn{2}{c}{ Total Keuntungan Usaha Kedai } \\
& Kopi dan Ratio R/C \\
\hline Uraian & \multicolumn{2}{c}{ Total } & Per bulan (Rp) \\
\hline Total Penerimaan & 13.505 .000 \\
Total Biaya Produksi & $9.296 .971,8$ \\
Keuntungan Usaha & $4.208 .028,2$ \\
Ratio R/C & 1,45 \\
\hline
\end{tabular}

Tabel 6, menunjukan bahwa R/C ratio usaha kedai kopi "Baba Budan" adalah sebesar 1,45 yang diperolah dari pembagian antara total penerimaan dengan total biaya produksi. Dapat disimpulkan bahwa usaha ini layak untuk dijalankan karena nilai $\mathrm{R} / \mathrm{C}$ lebih dari 1. Hal ini menunjukan bahwa setiap Rp. 1 biaya produksi yang dikeluarkan oleh pengelola kedai kopi mampu memberikan pengembalian penerimaan sebesar Rp. 1,45 yang artinya total penerimaan masih lebih tinggi dari total biaya produksi, sehingga usaha kedai kopi ini menguntungkan dan layak untuk dijalankan.

\section{KESIMPULAN DAN SARAN}

\section{Kesimpulan}

Hasil penelitian ini menunjukan bahwa :

Dari hasil penelitian yang telah dilakukan, dapat ditarik kesimpulan, bahwa rata-rata penerimaan dalam usaha ini mempunyai pengaruh positif dan signifikan terhadap keuntungan yang diperoleh oleh Kedai Kopi "Baba Budan". Hasil penelitian menunjukkan bahwa usaha dikawasan jalan roda mempunyai potensi.

\section{Saran}

Pengolahan hasil pertanian, khususnya industri kuliner dimana menjadi salah satu peluang usaha yang menawarkan keuntungan bagi para pelakunya. Salah satunya Kedai Kopi "Baba Budan" dikawasan wisata kuliner dijalan roda di Kota Manado, dan diharapkan menjadi bahan pertimbangan bagi instansi-instansi yang terkait untuk mengembangkan kawasan kuliner di jalan roda menjadi lebih baik, agar dapat memberikan dampak positif bagi Kota Manado. 


\section{DAFTAR PUSTAKA}

Aak, 1980. Budidaya Tanaman Kopi. Penerbit Yayasan Kanisius. Yogyakarta.

Dwi, R. 2003. Kewirausahaan Dari Sudut Pandang. Psikologi Kepribadian. Penerbit Grasindo. Jakarta.

Faizal, N. H. 2007. Ekonomi Manajerial. PT Raja Grafindo Persada. Jakarta.

Grace, M. 2014. Analisis Keuntungan Usaha Rumah Makan EL-shadai di Kawasan Wisata Kuliner "Wakeke Manado". Skripsi Jurusan Sosial Ekonomi Fakultas Pertanian Universitas Sam Ratulangi. Manado.

Harahap, S. 2009. Analisis Kritis Laporan Keuangan, Cetakan Ketiga, Edisi.1, Raja Grafindo Persada. Jakarta.

Kotler, P. 2006. Manajemen Pemasaran. Jilid 1. Edisi Kesebelas. PT. indeks. Jakarta.

Mangkunegara, 2002. Pengantar Manajemen Bisnis. PT. Remaja Rosdakarya. Bandung.

Najiyati dan Danarti, 2004. Kopi Budidaya dan Penanganan Lepas Panen,Edisi Revisi. Penerbit Swadaya. Jakarta.

Novianty, 2015. Analasis Keuntungan Usaha Sirup Segar CV. Segarindo Utama. Skripsi Jurusan Sosial Ekonomi Fakultas Pertanian Universitas Sam Ratulangi. Manado.

Panggabean, E. 2011. Buku Pintar Kopi. PT Agro Media Pustaka. Jakarta Selatan.
Primiana, I. 2009. Menggerakkan Sektor Riil UKM \& Industri. Penerbit Alfabeta. Bandung.

Rahardjo, P. 2012. Panduan Budidaya dan Pengolahan Kopi Arabika dan Robusta. Penerbit Swadaya. Jakarta.

Simamora, H. 2000. Manajemen Pemasaran Internasional. Penerbit Pustaka Utama, Surabaya.

Suryana, 2003. Kewirausahaan, Pedoman Praktis, Kiat dan Proses Menuju Sukses, PT.Salemba Empat. Jakarta.

Suryana, 2006. Kewirausahan Pedoman Praktis Kiat dan Proses Menuju. Sukses, Edisi Ketiga. Penerbit Salemba. Jakarta.

Suwardjono. 2008. Teori Akuntansi Perekayasaan Pelaporan Keuangan. Edisi Ketiga. Penerbit Grasindo. Yogyakarta.

Suyono, S. 2004. Pengkajian Potensi Kuliner Nusantara untuk Kemajuan Ekonomi Lokal. Penerbit FK UI. Jakarta.

Swastha, B. 2005. Analisa Pendapatan Usaha Kuliner. Penerbit Kanisius. Yogyakarta.

Tambunan, Tulus. 2002, Usaha Kecil dan Menengah di Indonesia Beberapa Isu Penting. Penerbit Salemba. Jakarta.

Tjiptono, F. 2001. Manajemen Jasa. Edisi Kedua. Penerbit Gramedia Pustaka Utama. Jakarta 
Wewengkang, D, S. dan Rotinsulu, H. 2017. Kewirausahaan, Penerbit CV. Patra

Wilson. 2007. Teori dan Analisi Biaya. Media Grafindo. Bandung.

\author{
Penerbit Grafindo. Jakarta
}

